\title{
PROPRIEDADES QUÍMICAS E CRISTALOGRÁFICAS DA CAULINITA E DOS ÓXIDOS DE FERRO EM SEDIMENTOS DO GRUPO BARREIRAS NO MUNICÍPIO DE ARACRUZ, ESTADO DO ESPÍRITO SANTO ${ }^{(1)}$
}

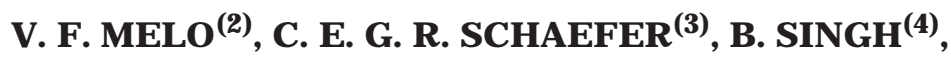 \\ R. F. NOVAIS ${ }^{(3)} \&$ M. P. F. FONTES ${ }^{(3)}$
}

\begin{abstract}
RESUMO
As propriedades químicas e cristalográficas detalhadas da caulinita (Ct) e dos óxidos de ferro do solo e dos sedimentos do Grupo Barreiras são pouco conhecidas. Para estudar as características desses minerais em profundidade, coletaram-se 11 amostras $(0,7 ; 1,4 ; 2,1 ; 2,8 ; 3,5 ; 4,2 ; 4,9 ; 5,6 ; 7,7 ; 10,5$ e 14 m) nos horizontes Bt, BC e C de um Argissolo Amarelo no município de Aracruz (ES). As frações argila e silte foram estudadas por difração de raios-X (DRX), análise termo-diferencial (ATD) e microscopia eletrônica. Os teores totais de Fe e outros microelementos ( $\mathrm{Cr}, \mathrm{Mn}, \mathrm{Ni}, \mathrm{Pb}, \mathrm{Ti}$ e $\mathrm{Zn}$ ) da fração argila foram determinados por espectrometria por emissão por plasma, após digestão da amostra com HF concentrado. Nos extratos resultantes das extrações com oxalato de amônio (OA) e ditionito-citrato-bicarbonato (DCB), determinaram-se os teores de Fe, Al, $\mathrm{Si}, \mathrm{Cr}, \mathrm{Mn}, \mathrm{Ni}$, Pb, Ti e Zn. A composição quími ca da Ct das frações argila (amostra desferrificada) e silte (amostra natural) foi determinada pelo tratamento com $\mathrm{NaOH} 5 \mathrm{~mol} \mathrm{~L}^{-1}$ e pela combinação de aquecimento e extração com $\mathrm{NaOH}$ 0,5 mol L-1 fervente, respectivamente. $\mathrm{O}$ teor médio de $\mathrm{Fe}_{2} \mathrm{O}_{3}$ da $\mathrm{Ct}$ da fração argi la $\left(20,7 \mathrm{~g} \mathrm{~kg}^{-1}\right)$ foi superior ao obtido para a fração silte $\left(5,2 \mathrm{~g} \mathrm{~kg}^{-1}\right)$, verificandose, na menor fração, aumento nos teores de $\mathrm{Fe}_{2} \mathrm{O}_{3} \mathrm{Com}$ a profundidade. Graças ao maior raio iônico, a presença do $\mathrm{Fe}^{3+}$ na estrutura promoveu aumento no espaço interplanar do mineral, sobretudo na di reção b. 0 tamanho das partículas de Ct foi semelhante entre os horizontes amostrados. A Ct apresentou grau semelhante de cristalinidade com a profundidade do solo, com exceção dos horizontes mais superficiais, os quais apresentaram menores valores de índice de cristalinidade, provavelmente por interferências com compostos orgânicos.
\end{abstract}

\footnotetext{
(1) Parte da Tese de Doutorado do primeiro autor. Recebido para publicação em outubro de 2000 e aprovado em setembro de 2001.

(2) Professor do Departamento de Solos, Universidade Federal do Paraná - UFPR. Rua dos Funcionários, 1540, Depto de Solos, J uvevê, CEP 80035-050 Curitiba (PR).

(3) Professor do Departamento de Solos, Universidade Federal de Viçosa - UFV. Av. PH Rolfs s/n, CEP $36571-000$ Viçosa (MG). Bolsista do CNPq.

(4) Professor, Department of Agricultural Chemistry and Soil Science, The University of Sydney, N.S.W. 2006, Australia.
} 
A redução dos teores de $\mathrm{Fe}_{2} \mathrm{O}_{3}$ extraídos pelo $\mathrm{DCB}$ e da participação dos teores deFeOA mais FeDCB no Fe total da fração argila com a profundidade foi atribuída à dissolu ção dos óxidos de ferro, provocada pela umidade nas camadas inferiores dos sedimentos. A substituição isomórfica (SI) de Fe por Al na goethita (Gt) foi cerca de três vezes superior à da hematita $(\mathrm{Hm})$, com maiores valores nos horizontes mais superficiais. A Hm apresentou menor valor de superfície específica (SE) que a Gt, refletindo os maiores valores de diâmetro médio do cristal para a Hm. Baixos valores de cristalinidade e menor tamanho de partículas estão associados à maior atividade e à influência da Ct e dos óxidos de ferro sobre as propriedades físico-químicas do solo. Os óxidos de ferro apresentaram baixa associação com microelementos, sobretudo com $\mathrm{Ni}, \mathrm{Pb}$ e Ti.

Termos de indexação: hematita, goethita, DRX, análises térmicas, microscopia eletrônica.

\title{
SUMMARY: CHEMICAL AND CRYSTAL PROPERTIES OF KAOLINITE AND IRON OXIDES IN THE BARREIRAS GROUP SEDIMENTS IN ARACRUZ, ESPÍRITO SANTO STATE, BRAZIL
}

\begin{abstract}
Detailed chemical and crystal properties of the kaolinite $(\mathrm{Ka})$ and iron oxides in the Barreiras Group soils and sediments (Coastal Tablelands) arelittleknown. Eleven samples were coll ected $(0,7 ; 1,4 ; 2,1 ; 2,8 ; 3,5 ; 4,2 ; 4,9 ; 5,6 ; 7,7 ; 10,5$ and $14 \mathrm{~m})$ in an exposed sediment sequence in Aracruz, Espírio Santo State, Brazil, in order to study the characteristics of these minerals with depth. Clay and silt fractions werestudied by $X$-ray diffraction (XRD), differential thermal analysis and electron mi croscopy. Total contents of $\mathrm{Fe}, \mathrm{Cr}, \mathrm{Mn}, \mathrm{Ni}, \mathrm{Pb}$, $\mathrm{Ti}$ and $\mathrm{Zr}$ of the clay fraction were determined by ICP after fluoridric acid extraction. The contents of $\mathrm{Al}, \mathrm{Si}$ and microelements were determined in ammonium oxalate (AO) and dithionite-citrate-bicarbonate (DCB) extracts. The chemical composition of kaolinite in the clay fraction was determined by extraction with $\mathrm{NaOH} 5 \mathrm{~mol} \mathrm{~L}^{-1}$ and in thesilt fraction by the combined heating and extracting with $\mathrm{NaOH} 0,5 \mathrm{~mol} \mathrm{~L}^{-1}$. Theaverage $\mathrm{Fe}_{2} \mathrm{O}_{3}$ content in thekaol inite of thed ay fraction $\left(20.7 \mathrm{~g} \mathrm{~kg}^{-1}\right)$ was higher than thoseobtained for thesilt fraction $\left(5.2 \mathrm{~g} \mathrm{~kg}^{-1}\right)$. Theinterplanar space, mainly in theb axis, was increased, dueto Fesubstitution in the kaolinite structure. The properties of kaolinite (such as size and shape) did not substantially differ with depth, although less crystall inekaolinitewas found at the surface, suggesting an interference of organic matter. With reference to the iron oxides, the $\mathrm{Fe}_{2} \mathrm{O}_{3}$ contents extracted by DCB in the clay fraction decreased with depth. The isomorphic substitution of Fefor $\mathrm{Al}$ was greater in goethite (Gt) in relation to hematite, with a trend of higher values at the sediment surface. The iron oxides presented little association with microelements, mainly, $\mathrm{Ni}, \mathrm{Pb}$ and $\mathrm{Ti}$.
\end{abstract}

Index terms: Hematite, goethite, XRD, thermal analysis, eletronic microscopy.

\section{NTRODUÇÃO}

Os sedimentos do Grupo Barreiras são argil osos, argilo-arenosos (Terciário) earenosos (Quaternário), de origem fluvial e ocupam a faixa litorânea e parte da sublitorânea de quase toda a Costa Oriental e Setentrional do Brasil, desde o Rio de J aneiro, estendendo-se para o norte até à Bacia Amazônica (Bigarella \& Andrade, 1964; Mabesoone \& Rolin, 1982).

A fração argila dos sedimentos é essencialmente caulinítica, sendo a presença de goethita e hematita limitada pelos baixos teores de ferro. São, portanto, sedimentos mineralogicamente bastante estáveis e resistentes ao intemperismo (E mbrapa, 1978; Mattos, 1979). Poucos estudos avaliam as características cristalográficas e químicas dos minerais presentes na fração argila destes sedimentos, tais como: cristalinidade, composição química, morfologia e tamanho de partículas, etc. A caulinita (Ct) e os óxidos de ferro, determinaram, normalmente, a cor e influenciam a estrutura, consistência, infiltração e retenção deágua e reações de troca iônica dos sol os.

A estrutura da Ct foi inicialmente detal hada por Grumer (1932) e, posteriormente, revisada por Brindley e colaboradores (Brindley \& Robinson, 
1947; Brindley, 1951; Brindley \& Nakashira, 1958). Vários procedimentos, baseados em difração de raios$\mathrm{X}$, têm sido propostos para estimar a cristalinidade da Ct (Hinckley, 1963; Hughes \& Brown, 1979; Artioli et al., 1995).

A Ct sob condições de clima tropical úmido apresenta, freqüentemente, baixo grau de cristalinidade (Hughes \& Brown, 1979; Singh \& Gilkes, 1992a), que depende de características químicas emorfológicas e defatores pedobiodimáticos. Por exemplo, a presença de $\mathrm{Fe}^{3+}$ na estrutura da $\mathrm{Ct}$ constitui um dos fatores quereduzem a cristalinidade e aumentama área superficial do mineral (Mestdagh et al., 1980; Brindley et al., 1986). A presença de interestratificação com minerais do tipo 2:1 (DeLuca \& Slaughter, 1985), de posições octaedrais vazias e preenchimento irregular do Al na camada octaédrica (Plançon et al., 1989) também são responsáveis pela redução da cristalinidade da Ct. Vários estudos identificaram interestratificação de esmectita e Ct (Schultz et al., 1971; Wiewiora, 1971; Yerima et al., 1985).

A forma da Ct varia desde partículas hexagonais até partículas com al to grau de desordem estrutural com forma tubular (Singh \& Gilkes, 1992a). As menores partículas de Ct apresentam baixo grau de cristalinidade e são desidroxiladas a menores temperaturas (Melo et al., 2001b).

Embora a Ct seja o principal mineral dos sedimentos, os óxidos de ferro normalmente estão presentes. A hematita $(\mathrm{Hm})$ e goethita (Gt) apresentam características mineralógicas distintas, como nível de substituição isomórfica de Fe por Al na estrutura, grau de cristalinidade, tamanho e forma do mineral, conforme o material de origem, estádio de intemperismo e condições biopedoclimáticas.

A substituição isomórfica de Fe por $\mathrm{Al}$ (SI) na estrutura da Gt e $\mathrm{Hm}$ é bastante comum e, como resultado, verificam-se mudanças no tamanho da cela unitária e cristalinidade da partícula (Taylor, 1987). Segundo Schwertmann \& Kämpf (1985), os mesmos fatores quefavorecem a formação da Gt são favoráveis à SI no mineral. Schwertmann et al. (1979) e Schwertmann (1985), trabalhando com óxidos de ferro sintéticos, estabel eceram o limite de $330 \mathrm{mmol} \mathrm{mol}^{-1}$ e $170 \mathrm{mmol} \mathrm{mol}^{-1}$ deSI na Gt eHm, respectivamente. Valores próximos a estes limites máximos para SI têm sido reportados para Gt e Hm de diferentes solos do Brasil (Kämpf et al., 1988; Fontes \& Weed, 1991).

Similarmente, outros cátions, comomicroel ementos ( $\mathrm{Ni}, \mathrm{Cr}, \mathrm{Co}, \mathrm{Cu}, \mathrm{Zn}, \mathrm{Ti}$, etc.), podem estar presentes na estrutura dos óxidos de ferro como substituintes do Fe (Schellman, 1983; Singh \& Glikes, 1992b).

O objetivo deste trabalho foi estudar as características químicas e cristalográficas da Ct e dos óxidos de ferro no sol o e no sedimento do Grupo Barreiras, no município de Aracruz (ES).

\section{MATERIAL E MÉTODOS}

\section{Amostragem}

Realizou-se a amostragem em 11 pontos às margens de um canal adutor de águas no município de Aracruz (ES), nas seguintes profundidades (valores após a correção da ded ividade, $45^{\circ}$, dotalude do canal): 0,$7 ; 1,4 ; 2,1 ; 2,8 ; 3,5 ; 4,2 ; 4,9 ; 5,6 ; 7,7 ; 10,5$ e $14 \mathrm{~m}$. A amostragem foi feita em um Argissolo Amarelo (E mbrapa, 1999), apresentando a seguinte distribuição e profundidade dos horizontes: $A$ $(0-16 \mathrm{~cm}), A B(16-25 \mathrm{~cm})$, Bt $(25-125 \mathrm{~cm}), B C$ (125-167 cm) e C (1,67-14,0 m+). As características morfológicas e a análise textural do sol o encontramsenoquadro 1. Durantea amostragem do horizonte C, foram separadas as camadas de sedimentos com características distintas, tais como: cor, presença de concreções de Fe e textura.

\section{Análises químicas e mineralógicas}

As amostras foram tratadas com hipoclorito de sódio, para remoção de matéria orgânica, e com $\mathrm{NaOH}$ 0,2 mol L-1, para dispersão das frações (J ackson, 1979). A fraçãoareia foi retida em peneira de $0,05 \mathrm{~mm}$ eas frações argila esilteforam separadas por sedimentação com basena lei deStokes (Gee\& Bauder, 1986).

Análise química - Para estudar a composição química dos óxidos de ferro menos cristalinos emais cristalinos, uma mesma amostra deargila, saturada com $\mathrm{Na}$, foi submetida a uma extração com oxalato de amônio (OA) 0,2 mol L-1, pH 3,0, na ausência de luz (McK eague, 1978), e a quatro extrações sucessivas com ditionito-citrato-bicarbonato (DCB) (Mehra \& J ackson, 1960). Após as extrações, a suspensão foi centrifugada, enquanto os extratos acondicionados para avaliar os teores de $\mathrm{Fe}, \mathrm{Al}$, Si e $\mathrm{Mn}$, para o $\mathrm{AO}$, e mais $\mathrm{Cr}, \mathrm{Mn}, \mathrm{Ni}, \mathrm{Pb}, \mathrm{Ti}$ e $\mathrm{Zn}$, para DCB. A dosagem dos el ementos foi feita em espectrômetro de emissão por plasma (Perkins Optima 3000). Os teores de Co, Cu e Cd não foram determinados por problemas analíticos.

Para estudar a composição química da caulinita (Ct), amostras desferrificadas da fração argila (após tratamento com DCB) foram tratadas com $\mathrm{NaOH}$ 0,5 mol L-1 fervente para remoção dealumina, sílica eal uminossilicatos de baixa cristal inidade ( $\mathrm{l}$ ackson, 1979; Melo et al., 2002ab). E m seguida, as amostras foram tratadas com $\mathrm{NaOH} 5 \mathrm{~mol} \mathrm{~L}^{-1}$, para extração da Ct (Norrish \& Taylor, 1961), e com HCl 0,5 mol L-1, para remoção da sodalita residual (Singh \& Gilkes, 1991). A remoção da Ct da fração silte foi obtida a partir de amostra natural (sem tratamento) pela combinação de aquecimento a $550^{\circ} \mathrm{C}$ por $4 \mathrm{~h}$ e extração com NaOH 0,5 mol L-1 fervente por 2,5 minutos ( ackson, 1979). Nos extratos obtidos dos tratamentos com NaOH $5 \mathrm{~mol} \mathrm{~L}^{-1}, \mathrm{HCl} 0,5 \mathrm{~mol} \mathrm{~L}^{-1} \mathrm{e}$ $\mathrm{NaOH} 0,5 \mathrm{~mol} \mathrm{~L}^{-1}$, foram determinados os teores de $\mathrm{Al}, \mathrm{Si}, \mathrm{Fe}, \mathrm{Ti}$ e Zr. 
Quadro 1. Características morfológicas e análise textural do pacote de sedimentos do Grupo Barreiras no município de Aracruz (ES)

\begin{tabular}{|c|c|c|c|c|c|c|c|c|}
\hline \multirow{2}{*}{ Horizonte } & \multirow{2}{*}{ Prof. } & \multirow{2}{*}{ Cor seco (Munsell) } & \multirow{2}{*}{ Concreção(1) } & \multicolumn{5}{|c|}{ Fração(2) } \\
\hline & & & & Argila & Silte & AF & AG & AT \\
\hline & $\mathrm{m}$ & & & & - & $\mathrm{kg}^{-1}$ & & ـ \\
\hline Bt & 0,7 & 10YR $7 / 4$ & & 463 & 52 & 133 & 352 & 485 \\
\hline$B C$ & 1,4 & $10 Y R 8 / 4$ & & 548 & 66 & 107 & 279 & 386 \\
\hline $\mathrm{C} 1$ & 2,1 & $5 Y R 7 / 4$ & Concreções de Fe ... & 572 & 58 & 91 & 279 & 370 \\
\hline C2 & 2,8 & $5 Y R 7 / 8$ & Concreções de Fe ... & 551 & 61 & 90 & 298 & 388 \\
\hline C3 & 3,5 & $5 Y R 7 / 6$ & & 494 & 21 & 96 & 390 & 486 \\
\hline C4 & 4,2 & $5 Y R 7 / 6$ & Concreções de Fe ... & 547 & 33 & 111 & 309 & 420 \\
\hline C5 & 4,9 & $5 Y R 8 / 4$ & Concreções de Fe ... & 542 & 39 & 129 & 290 & 419 \\
\hline C6 & 5,6 & Variegada $2,5 Y R$ R/4 e 7,5YR 8/1 & & 574 & 7 & 109 & 310 & 419 \\
\hline C7 & 7,7 & $5 Y R 8 / 4$ & Concreções de Fe ... & 266 & 23 & 91 & 620 & 711 \\
\hline C8 & 10,5 & Variegada 2,5YR 8/4 e 7,5YR 8/1 & Concreções de Fe ... & 527 & 14 & 86 & 373 & 459 \\
\hline C9 & 14,0 & Variegada 2,5YR 8/4 e N 8/ & & 669 & 4 & 58 & 269 & 327 \\
\hline
\end{tabular}

(1) Descrição morfológica, segundo Lemos \& Santos (1996). Horizontes C1, C4 e C7: concreção de Fe muito freqüente grande dura irregular vermel ho-escura a lilás. Horizontes C2, C5 e C8: concreção de Fe freqüente grande dura irregular vermel ho-escura a lilás. ${ }^{(2)} \mathrm{AF}$ - areia fina, AG - areia grossa e AT - areia total.

Os teores totais de Fe e outros microelementos $(\mathrm{Cr}, \mathrm{Mn}, \mathrm{Ni}, \mathrm{Pb}, \mathrm{Ti}$ e $\mathrm{Zn})$ da fração argila foram medidos por digestão da amostra com HF concentrado (Lim \& J ackson, 1986, com modificações propostas por Melo et al., 2002ab).

Difração de raios-X (DRX) - A Ct e os óxidos de ferro presentes na fração argila foram anal isados por DRX num difratômetro com goniômetro vertical Philips PW1050 controlado por computador com monocromador de grafite, radiação CuK $\alpha$ e operado a $40 \mathrm{kV}$ e $20 \mathrm{~mA}$.

Para os óxidos de ferro, amostras tratadas com $\mathrm{NaOH} 5 \mathrm{~mol} \mathrm{~L}^{-1}$ (remoção de Ct) foram montadas em lâmina (amostras não orientadas) e analisadas numa amplitude de 10 a $40^{\circ} 2 \theta$ e velocidade do goniômetro de $0,1^{\circ} 2 \theta / \mathrm{min}$. Utilizou-se $\mathrm{NaCl}$ como padrão interno na correção das distorções instrumentais (posição e largura à meia-altura dos picos). A partir dos difratogramas de raios-X, foram determinados a substituição isomórfica de Fe por Al (SI ) na estrutura da goethita (Gt) e hematita (Hm) (Schulze, 1984; Schwertmann et al., 1979), o diâmetro médio do cristal (DMC) (Klug \& Alexander, 1954) e a relação $\mathrm{Gt} /(\mathrm{Gt}+\mathrm{Hm})$ da fração argila (Torrent \& Cabedo, 1986).

Os val ores de superfície específica (SE ) para $\mathrm{Hm}$ e Gt foram obtidos por meio do DMC, com base na forma geométrica dos minerais, conforme dados de literatura. Para a Gt, admitiu-se o formato isodimensional (Schwertmann \& Kämpf, 1985; Fontes \& Weed, 1991) e para a Hm de placas circulares (Fontes \& Weed, 1991; Netto, 1996).
No estudo cristalográfico da Ct, utilizaram-se amostras desferrificadas (tratadas com DCB). A medição precisa da distância interplanar e a LMA das reflexões (001) e (002) foram feitas, utilizando n-octacoseno $\left[\mathrm{CH}_{3}\left(\mathrm{CH}_{2}\right)_{26} \mathrm{CH}_{3}\right]$ como padrão interno (lâminas orientadas) (Brindley \& Wan, 1974). O difratograma foi obtido numa escala horizontal de 3 a $30^{\circ} 2 \theta$ e a uma velocidade angular de $0,1^{\circ} 2 \theta / \mathrm{min}$. O índice de cristal inidade da Ct foi cal culadoa partir de difratogramas de amostras não orientadas, seguindo os procedimentos apresentados por Hughes \& Brown (1979).

Análise térmica - As análises termo-diferenciais das frações argila (amostra desferrificada) e silte (amostra natural) foram feitas em derivatógrafo Stanton Redcroft Série STA-780, sob atmosfera de $\mathrm{N}_{2}$ (Tan et al., 1986).

Superfície específica - A superfície específica de amostras da fração argila desferrificada foi determinada pelo método do $\mathrm{N}_{2}$-BET (Singh \& Gilkes, 1992a), usando o medidor de área superficial Micromeretics Gemini III 2375.

Microscopia eletrônica - Partículas de Ct da fração argila desferrificada e fração silte natural foram visualizadas e anal isadas quimicamente por microscopia el etrônica de transmissão (MET) e de varredura (MEV), respectivamente (Gilkes, 1994).

Foram feitas análises de correlações simples (Pearson) entre os teores dos elementos obtidos com as extrações dos óxidos de ferro e da Ct com características cristalográficas desses minerais, 
utilizando o programa estatísticoSAEG desenvol vido na Universidade Federal de Viçosa.

\section{RESULTADOS E DISCUSSÕES}

\section{Caulinita}

\section{Composição química}

A composição química da Ct das frações argila e silte não variou com a profundidade do solo (Quadro 2). Os teores de $\mathrm{SiO}_{2} \mathrm{eAl}_{2} \mathrm{O}_{3}$ estão de acordo com os dados compilados por Newman \& Brown (1987) para Ct presente em várias classes de solo.

A Ct da fração argila apresentou teores de $\mathrm{Fe}_{2} \mathrm{O}_{3}$ variando de 15,4 a 33,6 g kg-1 (Quadro 2). Nas profundidades de 10,5 e $14 \mathrm{~m}$, obtiveram-se os maiores teores de $\mathrm{Fe}_{2} \mathrm{O}_{3}$ e a relação $\mathrm{SiO}_{2} / \mathrm{Al}_{2} \mathrm{O}_{3}$ foi máxima, evidenciando a substituição do $\mathrm{Al}^{3+}$ por $\mathrm{Fe}^{3+}$. Vários autores, utilizando diferentes técnicas, relataram a presença de $\mathrm{Fe}^{3+}$ na camada octaédrica da Ct em substituição ao Al ${ }^{3+}$ (Herbillon et al., 1976; Mendelovici et al., 1979; Fysh et al., 1983). O coeficiente de correl ação ( $r$ ) entre $\mathrm{Fe}_{2} \mathrm{O}_{3}$ e a relação $\mathrm{SiO}_{2} / \mathrm{Al}_{2} \mathrm{O}_{3}$ foi de $0,95^{* * *}$. Em razão do maior raio iônico, a presença do $\mathrm{Fe}^{3+}$ na estrutura promoveu aumento no espaço interplanar da $\mathrm{Ct}$ na direção (060) ( $r$ entre $\mathrm{Fe}_{2} \mathrm{O}_{3}$ ed $(060)=0,74^{*}$ ). Rengasamy et al. (1975) e Singh \& Gilkes (1992a) também observaram aumento linear do parâmetro b da cela unitária, cal culado da reflexão (060), com aumento noteor de $\mathrm{Fe}_{2} \mathrm{O}_{3}$ na Ct. Melo et al. (2001b), utilizando o mesmo método de extração, encontraram teores de $\mathrm{Fe}_{2} \mathrm{O}_{3}\left(10,9\right.$ a $\left.28,9 \mathrm{~g} \mathrm{~kg}^{-1}\right)$ na Ct da fração argila de várias classes de solos do Brasil, próximos aos observados neste estudo.

A presença deTi foi maior na Ct da fração argila (média de 2,2 $\mathrm{g} \mathrm{kg}^{-1}$ ) do quena da fração silte (média de $0,33 \mathrm{~g} \mathrm{~kg}^{-1}$ ). Observações similares foram feitas por Nagelschmidt et al. (1949) em Ct padrão da Georgia. Os autores concluíram que a origem doTi era devida à associação da Ct com partículas de anatásio. Todas as amostras do presente estudo apresentaram anatásio na fração argila, com teor variando de 17 a $30 \mathrm{~g} \mathrm{~kg}^{-1}$ (Melo et al., 2002a). O Ti associado à $\mathrm{Ct}$ pode estar, em parte, presente na estrutura por substituição isomórfica (Dolcater et al., 1970; jepson \& Rowse, 1975) ou apenas adsorvido à superfície do mineral (Weaver, 1976).

\section{Características cristalográficas}

Interestratificações com minerais do tipo 2:1 e cristais com diferentes tamanhos são os principais motivos para variações na distância interplanar da Ct na direção (001) (Singh \& Gilkes, 1992a). Os val ores ded(001) para a Ct da fração argila variaram de 0,717 a 0,720 nm (Quadro 3). A variação nos valores ded(002) também foi bastante estreita $(0,358$ a $0,359 \mathrm{~nm}$ ). A pequena variação nas distâncias interplanares da Ct com a profundidade evidenciou a homogeneidade do mineral nos horizontes B e C. Da mesma forma, ainda com relação ao tamanho das partículas na direçãoc, verificou-sepequena variação nos valores de largura à meia-altura (LMA(001)), diâmetro médio do cristal (DMC(001)) e número médio de camadas (NMC) (Quadro 3).

A Ct apresentou grau semel hante de cristal inidade com a profundidade do solo, com exceção dos horizontes mais superficiais, os quais apresentaram menores valores de índice de cristalinidade de Hughes e Brown (ICHB), provavelmente por interferências com compostos orgânicos. Partículas de $\mathrm{Ct}$ de sol os desenvolvidos de outros materiais de origem e com diferentes estádios de intemperismo mostraram grandes variações nestes parâmetros [(LMA(001), DMC(001), N MC elCHB)]. Melo et al. (2001b) encontraram val ores de DMC(001), variando de 8,2 a $21,4 \mathrm{~nm}$, com média de $16,2 \mathrm{~nm}$, e valores

Quadro 2. Composição química da caulinita das frações argila e silte

\begin{tabular}{|c|c|c|c|c|c|c|c|c|c|c|c|}
\hline \multirow{2}{*}{ Horizonte } & \multirow{2}{*}{ Profundidade } & \multicolumn{6}{|c|}{ Fração argila } & \multicolumn{4}{|c|}{ Fração silte } \\
\hline & & $\mathrm{SiO}_{2}$ & $\mathbf{A l}_{2} \mathbf{O}_{3}$ & $\mathrm{Fe}_{2} \mathrm{O}_{3}$ & $\mathrm{TiO}_{2}$ & $\mathrm{ZrO}_{2}$ & $\mathrm{SiO}_{2} / \mathrm{Al}_{2} \mathrm{O}_{3}$ & $\mathrm{SiO}_{2}$ & $\mathbf{A l}_{2} \mathbf{O}_{3}$ & $\mathrm{Fe}_{2} \mathrm{O}_{3}$ & $\mathrm{TiO}_{2}$ \\
\hline & $\mathrm{m}$ & \multicolumn{6}{|c|}{$\mathrm{g} \mathrm{kg}^{-1}$} & \multicolumn{4}{|c|}{$\mathrm{g} \mathrm{kg}^{-1}$} \\
\hline Bt & 0,7 & 428,7 & 370,1 & 16,1 & 2,2 & 0,05 & 1,16 & 463,9 & 377,0 & 6,7 & 0,28 \\
\hline $\mathrm{BC}$ & 1,4 & 417,6 & 362,5 & 15,4 & 2,4 & 0,06 & 1,15 & 449,7 & 383,3 & 6,6 & 0,39 \\
\hline $\mathrm{Cl}$ & 2,1 & 427,7 & 370,5 & 16,1 & 2,6 & 0,06 & 1,15 & 459,7 & 382,6 & 5,3 & 0,37 \\
\hline $\mathrm{C} 2$ & 2,8 & 419,2 & 361,9 & 17,1 & 2,3 & 0,05 & 1,16 & 463,1 & 379,9 & 4,7 & 0,66 \\
\hline C3 & 3,5 & 422,4 & 367,3 & 17,3 & 2,6 & 0,04 & 1,15 & 452,7 & 370,2 & 5,9 & 0,34 \\
\hline C4 & 4,2 & 432,5 & 374,6 & 17,7 & 2,0 & 0,03 & 1,15 & 434,4 & 362,3 & 3,4 & 0,37 \\
\hline C5 & 4,9 & 416,5 & 359,7 & 17,7 & 1,6 & 0,03 & 1,16 & 447,6 & 369,5 & 3,7 & 0,22 \\
\hline C6 & 5,6 & 407,7 & 351,4 & 18,3 & 2,1 & 0,04 & 1,16 & 462,2 & 374,0 & 6,5 & 0,46 \\
\hline C7 & 7,7 & 417,0 & 357,6 & 20,0 & 1,6 & 0,03 & 1,17 & 435,9 & 357,3 & 1,4 & 0,11 \\
\hline $\mathrm{C} 8$ & 10,5 & 423,7 & 354,4 & 33,6 & 3,1 & 0,03 & 1,20 & 458,4 & 363,6 & 4,7 & 0,11 \\
\hline $\mathrm{C9}$ & 14,0 & 422,9 & 354,3 & 33,0 & 2,1 & 0,02 & 1,19 & 438,0 & 351,5 & 8,0 & 0,32 \\
\hline
\end{tabular}


Quadro 3. Propriedades da caulinita da fração argila e temperatura de desidroxilação da caulinita da fração silte ${ }^{(1)}$

\begin{tabular}{|c|c|c|c|c|c|c|c|c|c|c|}
\hline Horizonte & Profundidade & $\underset{(001)}{d}$ & $\begin{array}{c}d \\
(002)\end{array}$ & $\begin{array}{l}\text { LMA } \\
(001)\end{array}$ & $\begin{array}{l}\text { DMC } \\
(001)\end{array}$ & NMC & ICHB & SE & TDarg. & TDsilte \\
\hline & $\mathrm{m}$ & \multicolumn{2}{|c|}{$\mathrm{nm}$} & ${ }^{\circ} 2 \theta$ & $\mathrm{nm}$ & & & $\mathrm{m}^{2} \mathrm{~g}^{-1}$ & $\square^{\circ}$ & $\mathrm{C}$ \\
\hline Bt & 0,7 & 0,717 & 0,358 & 0,36 & 22,1 & 30,8 & 13,2 & 41,3 & 509 & 497 \\
\hline $\mathrm{BC}$ & 1,4 & 0,719 & 0,359 & 0,30 & 26,0 & 36,1 & 15,8 & 41,0 & 517 & 497 \\
\hline $\mathrm{C} 1$ & 2,1 & 0,721 & 0,358 & 0,29 & 27,0 & 37,5 & 16,0 & 38,2 & 518 & 503 \\
\hline $\mathrm{C} 2$ & 2,8 & 0,719 & 0,358 & 0,34 & 23,3 & 32,3 & 14,1 & 36,7 & 514 & 507 \\
\hline C3 & 3,5 & 0,718 & 0,358 & 0,31 & 25,2 & 35,1 & 19,3 & 36,5 & 514 & 501 \\
\hline $\mathrm{C} 4$ & 4,2 & 0,719 & 0,358 & 0,33 & 23,7 & 33,0 & 17,7 & 36,7 & 521 & 497 \\
\hline C5 & 4,9 & 0,719 & 0,358 & 0,35 & 22,6 & 31,4 & 22,7 & 38,1 & 515 & 500 \\
\hline $\mathrm{C} 6$ & 5,6 & 0,719 & 0,358 & 0,34 & 23,0 & 32,0 & 20,6 & 38,3 & 517 & 501 \\
\hline C7 & 7,7 & 0,720 & 0,358 & 0,36 & 21,7 & 30,2 & 19,4 & 39,1 & 517 & 496 \\
\hline C8 & 10,5 & 0,720 & 0,359 & 0,36 & 21,7 & 30,1 & 21,4 & 39,3 & 516 & 491 \\
\hline C9 & 14,0 & 0,718 & 0,358 & 0,39 & 20,3 & 28,3 & 19,8 & 41,8 & 506 & 499 \\
\hline
\end{tabular}

${ }^{(1)}$ Características determinadas por difração de raios-X: d(001), d(002) e LMA(001), distância interplanar e largura à meia-altura corrigidas pelo uso de padrão interno nas direções (001) e (002); DMC(001), diâmetro médio do cristal na direção (001); NMC, número médio de camadas [DMC(001)/d(001)]; ICHB, índice de cristalinidade de Hughes e Brown (Hughes \& Brown, 1979); SE, superfície específica determinada por sorção com $\mathrm{N}_{2}$; TDarg. eTdsilte, temperatura de desidroxilação da caulinita das frações argila e silte por análise termo-diferencial.

de ICHB, variando de 6,3 a 14,6, com média de 10,9.

Neste estudo, os valores médios de DMC(001) e ICHB foram de 23,3 nme 18,2, respectivamente. Os maiores valores médios dos dois parâmetros para Ct dos sedi mentos do Grupo Barreiras demonstraram a homogeneidade e maior pureza do material de origem em $\mathrm{Ct}$, com menor interferência de outros minerais e íons, permitindo maior crescimento e cristalinidadedomineral. A proporção deCt na fração argila foi alta e aumentou com a profundidade do solo, com teores de 870 e $953 \mathrm{~g} \mathrm{~kg}^{-1}$, nas profundidades de 0,7 e 14 m, respectivamente (Mel o et al., 2002a).

$O$ efeito da rocha de origem dos sedimentos e das condi ções cl imáticas da região sobre a concentração de Ct nos Tabuleiros Costeiros foi comentado por outros autores (Duarteet al., 2000; Meloet al., 2002a). Hughes \& Brown (1979) e Singh \& Gilkes (1992a), trabalhando com Ct padrão, encontraram ICHB variando de 38 a 83 . Outro fator que concorreu para aumentar o tamanho e cristalinidade do mineral foi o elevadoestádio de desenvolvimento dos sedimentos do Grupo Barreiras. Melo et al . (2001b) observaram que os Cambissolos originados de granito/gnaisse (Horizonte C), apresentaram valores muito inferiores de DMC(001) e ICHB, comparados com os de solos mais desenvolvidos. Singh \& Gilkes (1992a) obtiveram correlações significativas e positivas entre a capacidade de troca de cátions e índice de assimetria eSE para Ct dediferentes classes desolos.

Ainda com relação à importância da Ct sobre as propriedades físico-químicas do solo, esses autores verificaram que, quanto maiores a SE ea desordem estrutural (menor ICHB) das partículas, maior a adsorção de $\mathrm{P}$, fato atribuído à maior exposição de grupos Al-OH da camada octaédrica do mineral.

Neste estudo, a fração argila desferrificada também não apresentou grandes variações nos valores de superfície específica (SE) com a profundidade (Quadro 3), considerando a semel hança de tamanho das partículas de Ct.

Apesar de serem partículas maiores, a Ct da fração silte apresentou menor temperatura de desidroxilação (Quadro 3), provavel mente, em virtude do maior grau de desordem estrutural. Comportamento semel hante foi observado por Melo et al. (2001b).

\section{Microscopia eletrônica de transmissão (MET) e de varredura (MEV)}

Amostras de argila desferrificada e de silte sem tratamento, do horizonte C (2,1 e 5,6 m), foram estudadas por meio de MET e de MEV, respectivamente. A distribuição das formas das partículas de Ct (Figura 1 e Quadro 4) seguiu o padrão apresentado por Singh \& Gilkes (1992a). Analisaram-se cerca de 100 partículas para a distribuição das formas e obtenção de dimensões da Ct para cada profundidade. A percentagem de faces euédricas foi cal culada, dividindo-se o somatório do número de faces euédricas na amostra pel o número máximo possível (600 faces euédricas, considerando que $100 \%$ das partículas deveriam mostrar 6 faces).

A distribuição das formas da Ct nas profundidades de 2,1 e 5,6 foi bastante similar, com predomínio de formas alongadas e circulares. Mais de $50 \%$ das partículas não apresentaram faces euédricas e apenas $6,5 \%$ apresentaram forma hexagonal 
característica de Ct padrão (Hughes \& Brown, 1979; Singh \& Gilkes, 1992a). SegundoDixon (1989), a forma de pratos hexagonais deve-se ao empacotamento fechado dos oxigênios e hidroxilas em um padrão hexagonal.

Em minerais com baixa cristalinidade, este padrão não é observado, e as partículas não apresentaram as franjas deixadas pel o crescimento na direção c (ligações das unidades básicas) (Dixon, 1989). As interferências com partículas orgânicas e outros minerais contribuem para que as partículas de $\mathrm{Ct}$ apresentem poucas faces euédricas e, com o aumento do intemperismo, o mineral tende a perder as faces euédricas existentes (Singh \& Gilkes, 1992a; Melo et., 2001b). A Ct da fração silte apareceu na forma de agregados bastante estáveis (Figura 1 ), uma vez que resistiram à dispersão dos sedimentos com NaOH 0,2 mol L-1 e a vibrações ultra-sônicas durante a separação das frações.

As dimensões médias da Ct da fração argila nas direções a e b na profundidade de 5,6 m foram maiores (Quadro 4). Contudo, os mesmos valores obtidos para a SE nas profundidades de 2,1 e 5,6 m podem ser atribuídos ao maior $\mathrm{DMC}(001)$ para a menor profundidade (Quadro 3). A dimensão na direção a foi , em média, 40\% mai or que na direção b, para ambas as profundidades. Essa diferença deveuse ao predomínio das formas al ongadas, bem como ao fato de as formas euédricas com uma até quatro faces apresentarem, principalmente, formato alongado $(a>b)$. Os valores el evados para as relações a/DMC eb/DMC evidenciaram o crescimento preferencial da Ct nas direções a e b em detrimento da direção c (espessura).

Os teores de $\mathrm{TiO}_{2}$ e de $\mathrm{Fe}_{2} \mathrm{O}_{3}$, determinados por meio de microssonda de dispersão de raios- $X$ (MDRX) para a fração argila (Quadro 4), foram semelhantes aos obtidos pela análise química por meio da dissolução da Ct com $\mathrm{NaOH} 5 \mathrm{~mol} \mathrm{~L}^{-1}$ (Quadro 2). Os altos teores de $\mathrm{Fe}_{2} \mathrm{O}_{3}$ para a $\mathrm{Ct}$ da fração silte deveram-se ao recobrimento das partículas por óxidos de ferro, uma vez quea análise da fração silte por MDRX foi realizada em amostra sem tratamento prévio para remoção dos óxidos de ferro. Na profundidade de $2,1 \mathrm{~m}$, a concentração de $\mathrm{Fe}_{2} \mathrm{O}_{3}$ atingiu $220,1 \mathrm{~g} \mathrm{~kg}^{-1}$ (Quadro 4). (a)

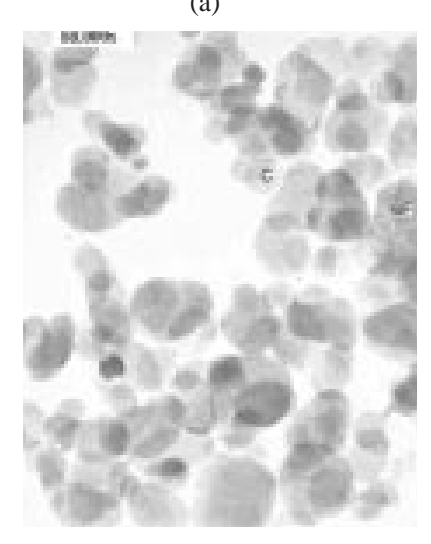

(c)

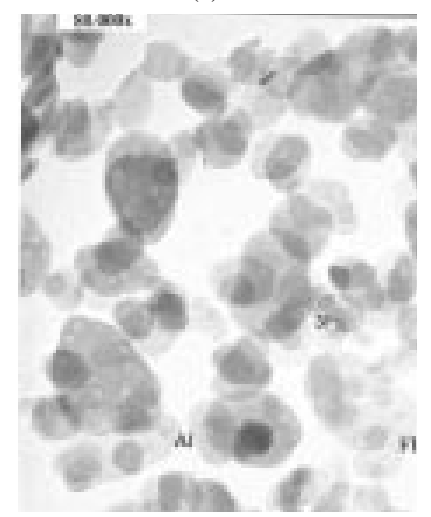

(b)

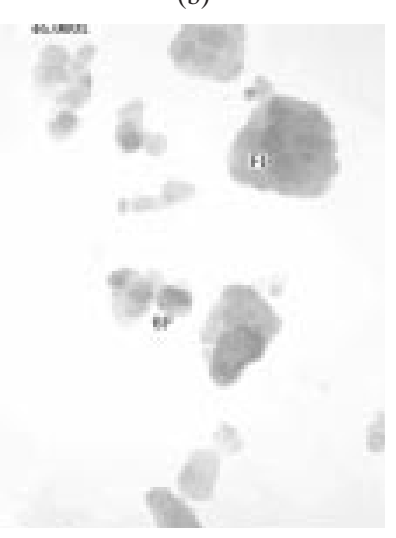

(d)

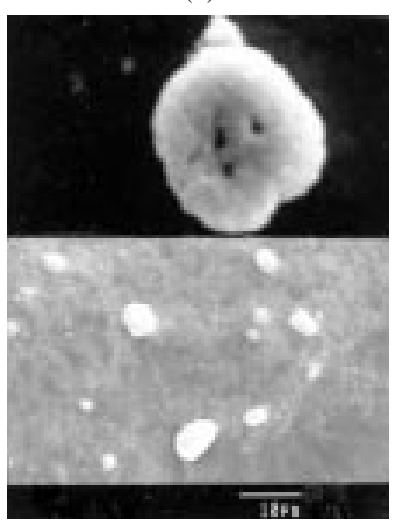

Figura 1. Fotomi crografias (MET) de partículas de caulinita da fração argila nas profundidades de 2,1 m (a e b) e 5,6 $\mathrm{m}$ (c ), com detalhe para as formas: alongada (AI), circular (C), indefinida (FI), 3 faces euédricas (3F) e 6 faces euédricas (6F), e micrografias (MEV) de partículas de caulinita da fração silte na profundidade de 2,1 $\mathrm{m}$ (d). 
Quadro 4. Estudo da forma e do tamanho da caulinita da fração argila (MET) e microanálise (MDRX) da caulinita das frações argila e silte

\begin{tabular}{|c|c|c|c|c|c|c|c|c|c|}
\hline \multirow{3}{*}{ Profundidade } & \multicolumn{9}{|c|}{ Distribuição da forma(1) } \\
\hline & \multicolumn{4}{|c|}{ Forma sem face euédrica } & \multicolumn{5}{|c|}{ Forma com face euédrica } \\
\hline & Al & C & $\mathbf{F I}$ & Total & 1-2 F & 3-4 F & $5 F$ & 6F & FE \\
\hline $\mathrm{m}$ & & & & & — $\%$ & & & & - \\
\hline \multirow{4}{*}{$\begin{array}{l}2,1 \\
5,6\end{array}$} & 26,6 & 22,9 & 1,3 & 50,8 & 24,2 & 16,1 & 2,4 & 6,5 & 23,5 \\
\hline & 33,1 & 22,0 & 1,0 & 56,1 & 18,7 & 18,7 & 0,0 & 6,6 & 21,8 \\
\hline & \multicolumn{9}{|c|}{ Tamanho das partículas(2) } \\
\hline & $a_{\max }$ & $a_{\min }$ & amed & $\mathbf{b}_{\max }$ & $\mathbf{b}_{\min }$ & $b_{\text {med }}$ & $a_{\text {med }} / b_{\text {med }}$ & a/DMC & b/DMC \\
\hline \multirow{4}{*}{$\begin{array}{l}2,1 \\
5,6\end{array}$} & 312 & 16 & 108 & 213 & 16 & 78 & 1,4 & 4,0 & 2,9 \\
\hline & 478 & 44 & 148 & 435 & 44 & 106 & 1,4 & 6,4 & 4,6 \\
\hline & \multicolumn{9}{|c|}{ Análise química } \\
\hline & $\mathrm{SiO}_{2}$ & $\mathrm{Al}_{2} \mathrm{O}_{3}$ & $\mathrm{Fe}_{2} \mathrm{O}_{3}$ & $\mathrm{TiO}_{2}$ & $\mathrm{~K}_{2} \mathrm{O}$ & $\mathrm{CaO}$ & MgO & \multicolumn{2}{|c|}{$\mathrm{SiO}_{2} / \mathrm{Al}_{2} \mathrm{O}_{3}$} \\
\hline $2,1^{(3)}$ & 516 & 459 & 19,5 & 1,1 & 1,1 & 2,1 & 1,9 & \multicolumn{2}{|c|}{1,12} \\
\hline $5,6(3)$ & 503 & 474 & 16,5 & 0,6 & 0,5 & 3,9 & 0,8 & \multicolumn{2}{|c|}{1,06} \\
\hline $2,1^{(4)}$ & 403 & 334 & 220,1 & 36,0 & 1,6 & 0,7 & 5,0 & \multicolumn{2}{|c|}{1,21} \\
\hline $5,6^{(4)}$ & 578 & 422 & 33,6 & 4,1 & 1,8 & 1,4 & 9,8 & \multicolumn{2}{|c|}{1,25} \\
\hline
\end{tabular}

(1) Al, C e FI, al ongada, circular e forma indefinida; Total, percentagem total das partículas sem faces euédricas; 1F, 2F, 3F, 4F, 5F e $6 \mathrm{~F}$, partículas com 1, 2, 3, 4, 5 e 6 faces euédricas; FE, percentagem de faces euédricas na amostra (ver observações no texto). (2) a e b, dimensões nas direções de maior e menor tamanho, respectivamente; a e b max, min e med, valores de a e b máximos, mínimos e médios; a/DMC e b/DMC, relações entre a e b médios e diâmetro médio do cristal na direção (001). (3)análise química da caulinita na fração argila. ${ }^{(4)}$ análise química da caulinita na fração silte.

\section{Óxidos de ferro}

Extração com oxalato de amônio (OA) e ditionito-citrato-bicarbonato (DCB)

O material extraído pelo OA é constituído, principalmente, por óxidos de alumínio menos cristalinos (65,5 a 82,7 \% de $\mathrm{Al}_{2} \mathrm{O}_{3}$ ) (Quadro 5). Dada a pobreza dos sedimentos em ferro, os teores de $\mathrm{Fe}_{2} \mathrm{O}_{3}$ foram superados até mesmo pelo $\mathrm{SiO}_{2}$. A única exceção foi observada na superfície onde a matéria orgânica favoreceu as formas de ferro de menor cristalinidade, por efeito de complexação (Blume \& Schwertmann, 1969). Elevadas quantidades de FeOA são associadas a horizontes que tenham alta carga dependente de pH ealta capacidade de fixação de P (McKeague \& Day, 1966).

Os teores de $\mathrm{Fe}_{2} \mathrm{O}_{3}$ pelo $\mathrm{DCB}$ diminuíram em profundidade, com exceção dos locais enriquecidos com ferro (principalmente em 2,1; 4,2; e 7,7 m) (Quadro 5). Nessas profundidades, os sedimentos apresentaram enriquecimento em Fe com concreções visualizadas em campo e em laboratório por meio de lupa (Quadro 1). J á a contribuição do $\mathrm{SiO}_{2}$ no material removido pelo DCB aumentou, atingindo o valor de $34 \%$ a 14 m de profundidade. Os menores valores para a relação FeOA/FeDCB, nas profundidades de 2,$1 ; 2,8 ; 4,2 ;$ e 7,7 m, deveram-se às condições verificadas nas concreções ferruginosas, ou seja, à alta proporção de óxidos de ferro na forma cristalina (Singh \& Gilkes, 1996).

A proporção (FeOA + FeDCB)/Fe total diminuiu em profundidade (Quadro 5). As condições de mai or umidade favoreceram a redução do ferro e a dissolução dos óxidos cristalinos, decrescendo a participação do FeOA e FeDCB no Fetotal. A maior parte do Fe total em profundidade encontra-se associada a minerais silicatados, principal mente $\mathrm{Ct}$ (Quadro 2). Outra possibilidade é a deposição de camadas de sedimentos mais pobres em óxidos de ferro nas maiores profundidades.

\section{Características cristalográficas}

Com base nas relações entre os valores de DMC (calculada a partir da LMA corrigida) da goethita (Gt) e hematita $(\mathrm{Hm})$, verificou-se que a $\mathrm{Hm}$ aproximou-se mais do formato isodimensional (relação DMC(110)/DMC(104) mais próxima de 1) (Quadro 6). Em razão dos mai ores val ores de DMC, a Hm apresentou menor superfície específica. Esse comportamento foi anteriormente verificado por outros autores (Schwertmann \& Kämpf, 1985; Kämpf et al., 1988). 
A substituição isomórfica de Fe por AI (SI) na estrutura dos óxidos de ferro foi maior para a Gt, em relação a Hm. A SI na Gt diminuiu com a profundidade (Quadro 5), provavel mente, em decorrência da menor atividade de Al na subsuperfície. Não houve associação entre SI na Gt e $\mathrm{Hm}(r=0,37)$. Considerando o maior grau de substituição na Gt, obteve-se correl ação significativa entre o teor de Al extraído pelo DCB e a SI nesse mineral $\left(r=0,85^{* *}\right)$. Dado o menor raio iônico do $\mathrm{Al}^{3+}$ em relação ao $\mathrm{Fe}^{3+}$, o tamanho da cela unitária, principalmente na direção c, mostrou-se reduzido com o aumento da SI (Fitzpatrick \& Schwertmann, 1982; Taylor, 1987). As correlações entre SI e distância interplanar (d) da Gt na direção(111) eSI e DMC(111) foram negativas e significativas ( $r=-0,95^{* * *} e-0,64^{*}$, respectivamente). Com a redução do tamanho das partículas com a SI , a Gt apresentou maior SE ( $r$ entre SI e SE $=0,73^{*}$ e entreDMC(111) e $\left.\mathrm{SE}=-0,99^{* * *}\right)$. A redução no tamanho da Gt constituiu um dos principais fatores responsáveis pel o aumento da capacidade de fixação deP pelo mineral (Bigham et al., 1978; Torrent et al., 1992).

A LMA da reflexão (111) da Gt pode ser usada como indicativo do grau de cristal inidade do mineral . Menores val ores de LMA(111) estão associados a Gt de maior grau de cristalinidade, com menor presença de Al na estrutura (menor SI) (Fitzpatrick \& Schwertmann, 1982). Neste estudo, a correlação entre LMA(111) eSI na Gt foi significativa $\left(r=0,74^{*}\right)$. Os valores de LMA da reflexão (111) da Gt mostraram-se maiores na superfície, indicando que a cristalinidade do mineral aumentou com a profundidade dos sedimentos (Quadro 6).

Quadro 5. Teores de elementos extraídos pelo oxalato de amônio (OA) e ditionito-citrato-bicarbonato (DCB) da fração argila

\begin{tabular}{|c|c|c|c|c|c|c|c|c|c|c|c|c|c|c|c|c|c|c|c|c|c|}
\hline \multirow{3}{*}{$\begin{array}{c}\text { Horiz } \\
\cdot\end{array}$} & \multirow{3}{*}{ Prof } & \multicolumn{9}{|c|}{ AO } & \multicolumn{9}{|c|}{ DCB } & \multirow{3}{*}{$\mathbf{R}^{(3)}$} & \multirow{3}{*}{$\mathbf{R}^{(4)}$} \\
\hline & & \multirow{2}{*}{$\mathrm{MnO}_{2}$} & \multirow{2}{*}{$\mathrm{Al}_{2} \mathrm{O}_{3}$} & \multirow{2}{*}{$\mathrm{Fe}_{2} \mathrm{O}_{3}$} & \multirow{2}{*}{$\mathrm{SiO}_{2}$} & \multirow{2}{*}{$\operatorname{Tot}^{(1)}$} & \multicolumn{4}{|c|}{ Relação ao total(2) } & \multirow{2}{*}{$\mathrm{MnO}_{2}$} & \multirow{2}{*}{$\mathrm{Al}_{2} \mathrm{O}_{3}$} & \multirow{2}{*}{$\mathrm{Fe}_{2} \mathrm{O}_{3}$} & \multirow{2}{*}{$\mathrm{SiO}_{2}$} & \multirow{2}{*}{$\operatorname{Tot}^{(1)}$} & \multicolumn{4}{|c|}{ Relação ao total(2) } & & \\
\hline & & & & & & & Al & $\mathbf{F e}$ & $\mathbf{S i}$ & Mn & & & & & & Al & $\mathrm{Fe}$ & $\mathbf{S i}$ & Mn & & \\
\hline & $\mathrm{m}$ & $\mathrm{mgkg}^{-1}$ & & $-g k$ & & & & — $\%$ & & - & $\mathrm{mgkg}^{-1}$ & & $-\mathrm{gkc}$ & & & & -\% & & & & \\
\hline Bt & 0,7 & 1,37 & 2,94 & 1,18 & 0,37 & 4,49 & 65,5 & 26,3 & 8,2 & 0,03 & 14,0 & 14,0 & 43,5 & 2,0 & 59,5 & 23,5 & 73,1 & 3,4 & 0,02 & 27,1 & 0,81 \\
\hline$B C$ & & 0,72 & & & & & 78,4 & & 9,4 & 0,02 & & & & & & & & 3,0 & & 8,1 & 0,82 \\
\hline $\mathrm{C} 1$ & 2,1 & 0,81 & 2,46 & 0,22 & 0,46 & 3,14 & 78,3 & 7,0 & 14,6 & 0,03 & 17,9 & 12,4 & 42,7 & 1,7 & 56,8 & 21,8 & 75,2 & 3,0 & 0,03 & 5,2 & 0,79 \\
\hline $\mathrm{C} 2$ & 2,8 & 0,61 & 2,0 & & 39 & & 78,4 & 6,3 & 15,3 & 0,02 & 13,3 & 8,9 & & & & & & 3,7 & & & 0,72 \\
\hline $\mathrm{C}$ & 3,5 & 0,75 & 2,39 & 0,15 & 0,48 & 3,02 & 79,1 & 5,0 & 15,9 & 0,02 & 7,7 & 5,8 & 22,6 & 1,8 & 30,2 & 19,2 & 74,8 & 6,0 & 0,03 & 6,6 & 0,60 \\
\hline C4 & 4,2 & 0,63 & 2,13 & 0,1 & 0,37 & 2,6 & 81,3 & 4,6 & 14,1 & 0,02 & 7, & 6,4 & 32, & 1, & & 15,8 & 79,4 & 4,7 & & 3,7 & 0,71 \\
\hline C5 & 4,9 & 0,44 & 3,10 & 0,18 & 0,47 & 3,75 & 82,7 & 4,8 & 12,5 & 0,01 & 4,3 & 4,4 & 23,6 & 2,6 & 30,6 & 14,4 & 77,1 & 8,5 & 0,01 & 7,6 & 0,60 \\
\hline C 6 & 5,6 & 0,97 & 2,28 & 0,16 & 0,53 & 2,97 & 76,7 & 5,4 & 17,8 & 0,03 & 1 , & 3,1 & 10 , & 2 , & 15 , & 19,6 & 63,9 & 16,5 & 0,01 & 15,8 & 0,37 \\
\hline C 7 & 7,7 & 0,80 & 2,21 & 0,20 & 0,44 & 2,85 & 77,5 & 7,0 & 15,4 & 0,03 & 4,4 & 4,4 & 33,8 & 1,8 & 40,0 & 11,0 & 84,5 & 4,5 & 0,01 & 5,9 & 0,72 \\
\hline C8 & 10,5 & 0,69 & 2,5 & 0,2 & 0,4 & 3,1 & 80 , & 6 & 13, & 0,0 & & 2 & 16 & & 22,6 & 11,5 & 74,8 & 13,7 & 0,01 & 11,8 & 0,38 \\
\hline C9 & 14,0 & 0,75 & 2,53 & 0,08 & 0,52 & 3,13 & 80,8 & 2,6 & 16,6 & 0,02 & 0,2 & 2,4 & 4,0 & 3,3 & 9,7 & 24,7 & 41,2 & 34,0 & 0,00 & 20,0 & 0,13 \\
\hline
\end{tabular}

(1) Tot, soma dos óxidos $\left(\mathrm{Al}_{2} \mathrm{O}_{3}+\mathrm{Fe}_{2} \mathrm{O}_{3}+\mathrm{SiO}_{2}+\mathrm{MnO}_{2}\right)$. (2) Participação de $\mathrm{Al}_{2} \mathrm{O}_{3}, \mathrm{Fe}_{2} \mathrm{O}_{3}, \mathrm{SiO}_{2}$ e $\mathrm{MnO}$ em relação ao total (soma dos óxidos). ${ }^{(3)}$ Relação ( $\left.\mathrm{Fe}_{2} \mathrm{O}_{3} \mathrm{OA} / \mathrm{Fe}_{2} \mathrm{O}_{3} \mathrm{DCB}\right) \times 10^{3}$. (4) Relação $\left(\mathrm{Fe}_{2} \mathrm{O}_{3} \mathrm{OA}+\mathrm{Fe}_{2} \mathrm{O}_{3} \mathrm{DCB}\right) / \mathrm{Fe}_{2} \mathrm{O}_{3}$ total da fração argila (digestão com $\mathrm{HF}$ concentrado).

\section{Quadro 6. Características da hematita ( $\mathrm{Hm})$ e goethita (Gt) presentes na fração $\operatorname{argila}^{(1)}$}

\begin{tabular}{|c|c|c|c|c|c|c|c|c|c|c|c|c|c|c|c|}
\hline \multirow{2}{*}{ Horiz. } & \multirow{2}{*}{ Prof. } & \multirow{2}{*}{$\mathbf{R} \mathbf{1}$} & \multirow{2}{*}{$\begin{array}{c}\text { LMA } \\
\text { Gt(111) }\end{array}$} & \multicolumn{5}{|c|}{ DMC } & \multirow{2}{*}{$\mathbf{R 2}$} & \multirow{2}{*}{$\mathbf{R 3}$} & \multirow{2}{*}{ R4 } & \multicolumn{2}{|c|}{ SE } & \multicolumn{2}{|c|}{ SI } \\
\hline & & & & Gt(110) & Gt(130) & Gt(111) & $\operatorname{Hm}(104)$ & $\operatorname{Hm}(110)$ & & & & Gt & $\mathrm{Hm}$ & Gt & $\mathrm{Hm}$ \\
\hline \multicolumn{3}{|c|}{$\mathrm{m}$} & ${ }^{\circ} 2 \theta$ & & & $-\mathrm{mm}$ & & - & & & & \multicolumn{2}{|c|}{$-\mathrm{m}^{2} \mathrm{~g}^{-1}-$} & \multicolumn{2}{|c|}{$-\mathrm{mmol} \mathrm{mol}^{-1}$} \\
\hline $\mathrm{Bt}$ & 0,7 & 1,00 & 0,45 & 30,80 & 20,70 & 18,49 & $*$ & $*$ & 1,67 & 1,49 & $*$ & 74,26 & $*$ & 277,8 & $*$ \\
\hline BC & 1,4 & 0,93 & 0,41 & 28,38 & 21,03 & 20,08 & 34,61 & 34,85 & 1,41 & 1,35 & 0,99 & 68,38 & 35,82 & 241,5 & 76,5 \\
\hline $\mathrm{C} 1$ & 2,1 & 0,85 & 0,41 & 33,69 & 20,25 & 20,22 & 42,28 & & 1,67 & 1,66 & & 67,90 & 32,36 & 202,9 & 76,5 \\
\hline$C 2$ & 2,8 & 0,78 & 0,43 & 31,08 & 15,18 & 19,11 & 39,94 & 34,55 & 1,63 & 2,05 & 1,16 & 71,85 & 34,14 & 237,2 & 76,5 \\
\hline $\mathrm{C} 3$ & 3,5 & 0,71 & 0,40 & & 26,15 & & 46,54 & & 1,33 & 1,06 & 0,63 & 66,14 & 20,73 & 187,9 & 76,5 \\
\hline C4 & 4,2 & 0,58 & 0,36 & 25,08 & nd & 22,84 & 51,37 & 63,48 & 1,10 & nd & 0,81 & 60,11 & 21,41 & 147,2 & 76,5 \\
\hline C5 & 4,9 & 0,59 & 0,24 & 27,48 & nd & 35,25 & 48,16 & & 0,78 & nd & 0,93 & 38,95 & 24,76 & 183,5 & 76,5 \\
\hline C6 & 5,6 & 0,58 & 0,27 & 24,05 & nd & 30,20 & 34,95 & 39,00 & 0,80 & nd & 0,90 & 45,46 & 33,36 & 145,0 & 51,8 \\
\hline C7 & 7,7 & 0,53 & 0,26 & 20,99 & nd & 32,33 & 26,19 & 45,56 & 0,65 & nd & 0,5 & 42,47 & 35,19 & 174,9 & 51,8 \\
\hline C8 & 10,5 & 0,25 & 0,28 & 16,87 & nd & 29,22 & 35,89 & 51,35 & 0,58 & nd & 0,70 & 46,99 & 28,31 & 160,1 & 88,8 \\
\hline C9 & 14,0 & 0,24 & 0,10 & nd & nd & nd & 42,16 & 42,16 & nd & nd & 1,00 & nd & 29,53 & 159,9 & 39,4 \\
\hline
\end{tabular}

(1) R1, relação Gt/(Gt + Hm); LMA, largura à meia-altura da reflexão (111) da Gt; DMC, diâmetro médio do cristal nas direções (110), (130) e (111) para a Gt e (104) e (110) para a Hm; R2, relação DMC Gt(110)/Gt(111); R3, relação DMC Gt(110)/Gt(130); R4, relação DMC Hm(110)/H m(104); SE, superfície específica; SI, substituição isomórfica de $\mathrm{Fe}^{3+}$ por $\mathrm{Al}^{3+}$. * = mineral ausente e nd =parâmetro não determinado. 
Quadro 7. Teores totais de microelementos extraídos pelo ácido fluorídrico concentrado (HF) e teores extraídos pelo ditionito-citrato-bicarbonato (DCB) da fração argila e fator de retenção de microelementos pelos óxidos de ferro

\begin{tabular}{|c|c|c|c|c|c|c|c|c|c|c|c|c|c|c|c|c|c|c|c|}
\hline \multirow{2}{*}{ Horiz. } & \multirow{2}{*}{ Prof. } & \multicolumn{6}{|c|}{ HF } & \multicolumn{6}{|c|}{ DCB } & \multicolumn{6}{|c|}{$F R^{(1)}$} \\
\hline & & $\mathrm{Cr}$ & Mn & $\mathbf{N i}$ & $\mathbf{P b}$ & $\mathbf{T i}$ & Zn & $\mathrm{Cr}$ & Mn & $\mathbf{N i}$ & $\mathbf{P b}$ & $\mathbf{T i}$ & $\mathrm{Zn}$ & $\mathrm{Cr}$ & Mn & $\mathbf{N i}$ & $\mathbf{P b}$ & $\mathbf{T i}$ & Zn \\
\hline & $\mathrm{m}$ & \multicolumn{12}{|c|}{$\mathrm{mg} \mathrm{kg}^{-1}$} & \multicolumn{6}{|c|}{ — $\%$} \\
\hline Bt & 0,7 & 78,2 & 62,2 & 23,9 & 13,8 & 14.575 & 55,1 & 12,6 & 9,1 & 0,5 & 2,3 & 23,2 & 12,8 & 19,8 & 18,1 & 2,7 & 20,4 & 0,2 & 28,6 \\
\hline BC & 1 , & 79,5 & 54,5 & 21,7 & 22,2 & 13.5 & 99,8 & 17,4 & 10,0 & 0,2 & 2,0 & 26,2 & & 26,2 & 22,0 & 1,0 & 10,8 & 2 & 10,2 \\
\hline $\mathrm{C} 1$ & 2,1 & 81,4 & 50,9 & 19,2 & 25,1 & 13.583 & 102,9 & 17,2 & 11,6 & 0,8 & 2,4 & 30,8 & 10,1 & 26,2 & 28,4 & 5,4 & 11,7 & 0,3 & 12,2 \\
\hline $\mathrm{C} 2$ & 2,8 & 85,4 & 47,2 & 24,8 & 42,7 & & & 17,5 & & 0,0 & 1,3 & 25,4 & & & & 0,0 & 4,2 & & 14,9 \\
\hline C3 & 3,5 & 104,6 & 42,3 & 24,2 & 67,0 & 18.208 & 67,9 & 17,8 & 5,0 & 0,3 & 1,6 & 19,2 & 6,7 & 28,1 & 19,7 & 2,0 & 4,0 & 0,2 & 16,4 \\
\hline $\mathrm{C} 4$ & 4,2 & & 34,2 & 29,5 & 60,4 & 16.3 & 59,7 & 18,5 & 5,0 & 0,3 & 3,0 & 24,9 & 9,3 & 26,1 & 20,2 & 1,3 & 7,0 & 2 & 21,5 \\
\hline C5 & 4,9 & 101,3 & 29,6 & 28,8 & 56,5 & 16.993 & 70,7 & 15,6 & 2,8 & 0,8 & 1,4 & 20,5 & 35,0 & 25,4 & 15,8 & 4,4 & 4,0 & 0,2 & 81,7 \\
\hline $\mathrm{C} 6$ & 5,6 & 93,9 & 19,5 & 31,4 & 58,3 & 14.286 & 82,7 & 11,0 & 1,1 & 1,4 & 0,0 & 10,9 & 10,3 & 32,1 & 15,4 & 11,9 & 0,0 & 0,2 & 34,2 \\
\hline C7 & 7,7 & & 23,9 & 30,3 & 115,3 & 13.096 & 71,1 & 18,6 & 2,9 & 0,2 & 2,1 & 18,0 & 10,3 & 29,1 & 16,8 & 1,1 & 2,5 & 0,2 & 20,4 \\
\hline C8 & 10,5 & 103,7 & 16,7 & 21,2 & 83,9 & 12.966 & 112,5 & 10,1 & 0,9 & 0,3 & 0,1 & 15,6 & 12,0 & 25,9 & 13,7 & 4,2 & 0,3 & ,3 & 28,4 \\
\hline C9 & 14,0 & 86,7 & 8,0 & 19,8 & 65,7 & 10.359 & 60,7 & 3,5 & 0,1 & 0,9 & 1,1 & 5,2 & 3,9 & 32,7 & 10,7 & 37,8 & 13,9 & 0,4 & 51,6 \\
\hline
\end{tabular}

(1) Fator de retenção calculado segundo fórmula apresentada por Singh \& Gilkes (1992b): FR do elemento y =[(teor de y nos óxidos de ferro/teor de y na fração argila) x (teor de Fe nos óxidos de ferro/teor de Fe na fração argila)] x 100.

\section{Presença de microelementos na estrutura dos óxidos de ferro}

Vários autores relataram a presença de microel ementos na estrutura dos óxidos de ferro, por meio de substituição isomórfica (Schellman, 1983; Singh \& Gilkes; 1992b). Os teores totais dos microelementos extraídos pelo HF foram bem superiores aos teores obtidos com DCB (Quadro 7), mostrando que apenas pequena parte dos microelementos presentes na fração argila estava associada aos óxidos de ferro. Os baixos valores dos fatores de retenções (FR) de microelementos pelos óxidos de ferro evidenciaram este comportamento (Quadro 7). A maior afinidade dos óxidos de ferro foi verificada para Zn, $\mathrm{Cr}$ e Mn, com retenção média de 29,$1 ; 27,3$ e $18,7 \%$, respectivamente.

$\mathrm{O} \mathrm{Ni}, \mathrm{Pb}$ e Ti praticamente não se associaram aos óxidos de ferro (retenção média de 6,7; 7,2 e 0,2\%, respectivamente). Singh \& Gilkes (1992b) e Melo et al. (2001a) encontraram valores maiores para o FR em diferentes classes de solos. Os baixos val ores de retenção para Ti foram atribuídos à presença de anatásio na fração argila (Melo et al.,2002a), el evando os teores totais do elemento.

\section{CONCLUSÕES}

1. O teor médio de $\mathrm{Fe}_{2} \mathrm{O}_{3}$ da caulinita $(\mathrm{Ct})$ da fração argila $\left(20,7 \mathrm{~g} \mathrm{~kg}^{-1}\right)$ foi superior ao obtido para a fração silte $\left(5,2 \mathrm{~g} \mathrm{~kg}^{-1}\right)$, verificando-se, na menor fração, aumento nos teores de $\mathrm{Fe}_{2} \mathrm{O}_{3} \mathrm{com}$ a profundidade do solo, provavel mente por estar o $\mathrm{Fe}^{3+}$ substituindo o $\mathrm{Al}^{3+}$ na camada octaédrica da Ct. Graças ao maior raio iônico, a presença do $\mathrm{Fe}^{3+}$ na estrutura promoveu aumento no espaço interplanar do mineral.

2. O tamanho das partículas de Ct foi semelhante entre as diferentes profundidades amostradas. A Ct apresentou grau semelhante de cristalinidade com a profundidade, com exceção dos horizontes mais superficiais, os quais apresentaram menores valores de índice de cristalinidade, provavelmente por interferências com compostos orgânicos.

3. O material extraído pelo oxalato de amônio (OA), é constituído, principalmente, por óxidos deAI menos cristalinos $\left(65,5\right.$ a $82,7 \%$ de $\left.\mathrm{Al}_{2} \mathrm{O}_{3}\right)$. Com exceção dos locais do pacote de sedimentos enriquecidos com ferro, os teores de $\mathrm{Fe}_{2} \mathrm{O}_{3}$ extraídos pelo ditionito-citrato-bicarbonato (DCB) e a partici pação dos teores de FeOA mais FeDCB no Fe total da fração argila diminuíram com a profundidade do solo.

4. A substituição isomórfica (SI) de Fe por Al na goethita (Gt) foi cerca de três vezes superior à da hematita $(\mathrm{Hm})$, com maior valores próximos à superfície do solo. A Hmapresentou menor valor de superfície específica (SE) que a Gt, refletindo os maiores valores de diâmetro médio do cristal para a $\mathrm{Hm}$.

5. Os óxi dos de ferro apresentaram baixa associação com microel ementos, sobretudo com Ni, Pb e Ti.

\section{LITE RATURA CITADA}

ARTIOLI, G.; BELLOTTO, M.; GUALTIERI, A. \& PAVESE, A. Nature of structural disorder in natural kaolinites: a new model based on computer simulation of powder diffraction data and el ectrostatic energy cal culation. Clays Clay Miner., 43:438-445, 1995. 
BIGARELLA, J J . \& ANDRADE, G.O. Considerações sobre a estratigrafia dos sedimentos cenozóicos em Pernambuco (Grupo Barreiras). Univ. Recife Arq. Inst. Ci. Terra, 2:114, 1964.

BIGHAM, J.M.; GOLDEN, D.C.; BUOL, S.W.; WEED, S.B. \& BOWEN, L.H. I ron oxide mineralogy of well-drained UItisols and Oxisols: II. Influence on color, surface area, and phosphate retention. Soil Sci. Soc. Am J ., 42:825-830, 1978.

BLUME, H.P. \& SCHWERTMANN, U. Genetic evaluation of profile distribution of aluminium, iron, and manganese oxides. Soil Sci. Soc. Am. Proc., 33:438-444,1969

BRINDLEY, G.W. X-ray identification and crystal structures of clay minerals. London, Mineralogical Society, 1951. p.3275 .

BRINDLEY, G.W.; KAO, CHIH-CHUN; HARRISON, J.L.; LIPSCAS, M.L. \& RAYTHATHA, R. Relation between structural disorder and other characteristicas of kaolinite and dickites. Clays Clay Miner., 34:239-249, 1986.

BRINDLEY, G.W. \& NAKASHIRA, M. Further consideration of crystal structure of kaolinite. Miner. Mag., 31:781-786, 1958.

BRINDLEY, G.W. \& ROBINSON, K. The structure of kaolinite. Mineral. Mag., 27:242-253, 1947.

BRINDLEY, G.W. \& WAN, H.M. Use of long al cohols and alkanes for calibration of long spacings from layer silicates, particularly Clay Miner. Clays Clay Miner., 22:313-317, 1974.

DeLUCA, S. \& SLAUGHTER, M. Existence of multiple phases and their relationship to disorder in kaolin minerals. Am. Miner., 70:149-158, 1985.

DIXON, J.B. Kaolin and serpentine group minerals. In: DIXON, J.B \& WEED, S.B., eds. Minerals in soil environments. Madison, Soil Science Society of America, 1989. p.467 525.

DOLCATER, D.L.; SYERS, J .K. \& J ACKSON, M.L. Titanium as free oxide and substituted forms in kaolinite and other soil minerals. Clays Clay Miner., 18:71-79, 1970.

DUARTE, M.N.; CURI, N.; PÉREZ, D.V.; KÄMPF, N. \& CLAESSEN, M.E.C. Mineralogia, química e micromorfologia de sol os de uma microbacia nos Tabuleiros Costeiros do Espírito Santo. Pesq. Agropec. Bras., 35:1237$1250,2000$.

EMPRESA BRASILEIRA DE PESQUISA AGROPECUÁRIA EMBRAPA. Levantamento de reconhecimento dos solos do Estado do Espírito Santo. Rio de J aneiro, 1978. 461p. (Bol etim Técnico, 45)

EMPRESA BRASILEIRA DE PESQUISA AGROPECUÁRIA EMBRAPA. Centro Nacional de Pesquisas de Solos. Rio de J aneiro. Sistema Brasileiro de Classificação de Solos. Brasília, Serviço de Produção de Informação - SPI, 1999. 412p.

FITZPATRICK, R.W. \& SCHWERTMANN, U. Al-substituted goethite - An indicator of pedogenic and other weathering environments in South Africa. Geoderma, 27:335-347, 1982.
FYSH, S.A.; CASHION, J.D. \& CLARK, P.E. Mösbauer effect studies of iron in kaolin I. Structural iron. Clays Clay Miner., 32:285-292, 1983.

FONTES, M.P.F. \& WEED, S.B. I ron oxides in selected Brazilian Oxisols. I. Mineralogy. Soil Sci. Soc. Am. J., 55:11431149, 1991.

GILKES, R.J . Transmission Electron Microscopy analysis of soil materials. Quantitative Methods in Soil Mineralogy. Madson, Soil Science Society of America, 1994. p177-204.

GRUMER, J.W. The crystal structure of kaolinite. Z. Kristallogr. Kristallgeom., 83:75-80, 1932.

HERBILLON, A.J.; MESTDAGH, M.M.; VIELVOYE, L. \& DEROUANE, E.G. I ron in kaolinite with special reference to kaolinite from tropical soils. Clay Miner., 11:201-220, 1976.

HINCKLEY, D.N. Variability in "cristalinity" values among the kaolinites deposits of the coastal plain of Georgia and South Carolina. Clays Clay Miner., 11:229-235, 1963.

HUGHES, J.C \& BROWN, G. A crystallinity index for soil kaolinite and its relation to parent rock, climate and soil maturity. J. Soil Sci., 30:557-563, 1979.

JACKSON, M.L. Soil chemical analysis - advanced course. Madison, Prentice-Hall, 1979. 895p.

J EPSON, W.B. \& ROWSE, J.B. The composition of kaolinite - An electron microscopy microprobe study. Clays Clay Miner., 23:310-317, 1975.

KÄMPF, N.; RESENDE, M. \& CURI, N. I ron oxides in Brazilian soils. In: INTERNATIONAL SOIL CLASSIFICATION WORSHOP, 8., Curitiba, 1988, Anais. Curitiba, Empresa Brasileira de Pesquisa Agropecuária, Universidade Federal do Paraná, 1988. p.71-77.

KLUG, H.P. \& ALEXANDER, L.E. X-ray diffraction procedures for polycrystalline and amorphous materials. New York, J ohn Wiley \& Sons, 1954. 716p.

LEMOS, R.C. \& SANTOS, R.D. Manual de descrição e col eta de sol os no campo. 3.ed. Campinas, Sociedade Brasileira de Ciência do Solo, 1996. 85p.

LIM, C.H. \& J ACKSON, M.L. Dissolution for total elemental analysis. In: PAGE, A.L., ed. Methods of soil analysis. Parte 2: Chemical and microbiological properties. Madison, American Society of Agronomy, 1986. p.1-12.

MABESOONE, J.M. \& ROLIM, J.L. Problemas estratigráficos e sedimentológicos do cenozóico nordestino. Estudos Pesq., 5:7-18, 1982

MATTOS, C.M. Propriedades físicas de sol os cauliníticos coesos do município de Aracruz, ES. Piracicaba, Escola Superior de Agricultura Luiz de Queiroz, 1979. 73p. (Tese de Mestrado)

McKEAGUE, J.A. Manual on soil sampling and methods of analysis. Ottawa, Can. Soc. Soil Sci., 1978. 212p.

McKEAGUE,J .A. \& DAY,J.H. Dithioniteand oxalate-extractable Fe and $\mathrm{Al}$ as aids in differentiating various classes of soils. Can. J. Soil Sci., 46:13-22, 1966. 
MEHRA, O.P. \& J ACKSON, M.L. I ron oxide removal from soils and clay by a dithionite-citratesystem bulfered with sodium bicarbonate. Clays Clay Miner., 7:317-327, 1960.

MELO, V.F.; FONTES, M.P.F.; NOVAIS, R.F.; SINGH, B. \& SCHAEFER, C.E.G.R. Características dos óxidos de ferro e de alumínio de diferentes classes de solos. R. Bras. Ci. Solo, 25: 19-32, 2001a.

MELO, V.F.; SINGH, B.; SCHAEFER, C.E.G.R.; NOVAIS, R.F. \& FONTES, M.P.F.F. Chemical and mineralogical properties of kaolinite-rich Brazilian soils. Soil Sci. Soc. Am. J., 65:1324-1333, 2001b.

MELO, V.F.; NOVAIS, R.F.; SCHAEFER, C.E.G.R.; FONTES, M.P.F.F. \& SINGH, B. Mineralogia das frações areia, silte eargila de sedimentos do Grupo Barreiras no município de Aracruz, estado do Espírito Santo. R. Bras. Ci. Solo, 26:29$41,2002 a$.

MELO, V.F.; SCHAEFER, C.E.G.R.; NOVAIS, R.F.; SINGH, B. \& FONTES, M.P.F.F. Potassium and magnesium reserve in clay minerals of some Brazilian soils, as indicated by sequential extraction procedure. Comm. Soil Sci. Plant An., 2002b. (in publication)

MENDELOVICI, E.; YARIV, S. \& VILLALBA, R. I ron bearing kaolinite in Venezuelan laterites. I. Infrared spectroscopy and chemical dissolution evidence. Clays Clay Miner., 14:323-331, 1979.

MESTDAGH, M.M.; VIELVOYE, L. \& HERBILLON, A.J . Iron in kaolinite: II. The relationship between kaolinite crystallinity and iron content. Clay Miner., 15:1-13, 1980.

NAGELSCMIDT, G.; DONNELLY, H.F. \& MORCOM, A.J . On the occurrence of anatase in sedimentary kaolin. Miner. Mag., 28:492-495, 1949.

NETTO, A.R. I Influência da mineralogia da fração argila sobre propriedades físico-químicas de solos brasileiros. Viçosa, Universidade Federal de Viçosa, 1996. 144p. (Tese de Mestrado)

NEWMAN, A.C.D. \& BROWN, G. The chemical constitution of clays. In:BROWN, G., ed. Chemitry of days and day minerals. Madson, Mineralogycal Society, Longman Scientific \& Technical, 1987. p.1-128.

NORRISH, K.\& TAYLOR, M. The isomorphous replacement of iron by aluminium in soil goethites. J. Soil Sci., 12:294306, 1961.

PLANÇON, A.; GIESE, R.F.; SNYDER, R.; DRITS, V.A. \& BOOKIN, A.S. Staking faults in the kaolin minerals. Clay Clays Miner., 37:203-210, 1989.

RENGASAMY, P.; KRISMA MURTI, G.S.R. \& SARMA, V.A.K. Isomorphous substitution of iron for aluminium in some soil kaolinites. Clays Clay Miner., 23:211-214, 1975.

SCHELLMAN, W. Geochemical principles of lateritic nickel ore formation. Lateritisation Processes. In: I NTERNATIONAL SEMINAR ON LATERITISATION PROCESSES, 2., São Paulo, 1983. Anais. São Paulo, Instituto Astronômico e Geofísico, Universidade de São Paulo, 1983. p.119-135.
SCHULZE, D.G. The influence of aluminium on iron oxides. VIII - unit-cell dimensions of Al-substituted goethites and estimation of Al from them. Clays Clays Miner., 32:36:44, 1984.

SCHULTZ, L.G.; SHEPARD, A.O.; BLACKMON, P.D. \& STARKEY, H.C. Mixed-layer kaolinite-montmorillonite from the Yucatan Peninsula, Mexico. Clays Clay Miner., 19:137-150, 1971.

SCHWERTMANN, U. The effect of pedogenic environments on iron oxide minerals. Adv. Soil Sci., 1:171-200, 1985.

SCHWERTMANN, U.; FITZPATRICK, R.W.; TAYLOR, R.M. \& LEWIS, D.G. The influence of aluminium on iron oxides. Part II. Preparation and properties of Al-substituted hematites. Clays Clays Miner., 29:269-276, 1979.

SCHWERTMANN, U. \& KÄMPF, N. Properties of goethite and hematite in kaolinitic soils of Southern and Central Brazil. Soil Sci., 139:344-350, 1985.

SINGH, B. \& GILKES, R.J. Concentration of iron oxides from soil clays by $5 \mathrm{M} \mathrm{NaOH}$ treatment: The complete removal of sodalite and kaolin. Clay Miner., 26:463-472, 1991.

SINGH, B. \& GILKES, R.J. Properties of soil kaolinites from south-westen Australia. J. Soil Sci., 43:645-667, 1992a.

SINGH, B. \& GILKES, R.J. Properties and distribution of iron oxides and their asociation with minor elements in the soils of south-western Australia. J. Soil Sci., 43:77-98, 1992b.

SINGH, B. \& GILKES, R.J. Nature and properties of iron rich glaebules and mottles from some south-west Australian soils. Geoderma, 71:95-120, 1996.

TAN, K.B.; HAJ EK, B.F. \& BARSHAD, I. Thermal analysis techniques. In: KLUTE, A., ed. Methods of soil analysis. Parte 1: Physical and mineralogical methods. Madison, American Society of Agronomy, 1986. p.151-183.

TAYLOR, R.M. Non-silicate oxides and hydroxides. In: NEWMAN, A.C.D., ed. Chemistry of clays and clay minerals. London, Mineralogical Society, 1987. p.129-201.

TORRENT, J \& \& CABEDO, A. Sources of iron oxides in reddish brown soil profiles from calcarenites in Southern Spain. Geoderma, 37:5766, 1986.

TORRENT, J .; SCHWERTMANN, U. \& BARRÓN, V. Fast and slow phosphatesorption by goethite-rich natural materials. Clays Clays Miner., 40:14-21, 1992.

YERIMA, B.P.K.; CALHOUN, F.G.; SENKAYI, A.L. \& DIXON, J.B. Ocurrence of interstratified kaolinite-smectite in EI Salvador Vertisols. Soil Sci. Soc. Am. J., 49:462-466, 1985.

WEAVER, C.E. The nature of $\mathrm{TiO}_{2}$ in kaolinite. Clays Clay Miner., 24:215-218, 1976

WIEWIORA, A. A mixed-layer kaolinite-smectite from lowwer Silesia, Poland. Clays Clay Miner, 19:415-416, 1971. 